\title{
Multiple Stress Creep Recovery (MSCR) Test for Determination of Waste Engine Oil Modified Asphalt Binder as Pavement Material
}

\author{
Biruk Tadele ${ }^{1,}{ }^{*}$, Emer T. Quezon ${ }^{2}$ \\ ${ }^{1}$ Department of Civil Engineering, Haramaya Institute of Technology, Haramaya University, Ethiopia \\ 2 Department of Civil Engineering, Addis Ababa science and Technology University, Addis Ababa, Ethiopia \\ ${ }^{*}$ Corresponding authors email: biruk.tadele@aastu.edu.et \\ DOI: https://doi.org/10.54392/irjmt2212 \\ Received: 14-12-2021, Revised: 29-12-2021; Accepted: 30-12-2021, Published: 01-01-2022
}

\begin{abstract}
Engineers have been using modified binders to improve the quality of flexible pavements. The use of waste material is one of the solutions taken in this direction. It is for this ground that the studies emphasis on the evaluation of waste engine oil as a modifier for asphalt binder as a pavement material. In the study uses four samples extracted from 80/100 penetration grade bitumen. From four sample first sample was checked for weather requirements of asphalt binder meet or not and the three were modified with different content of engine oil (3,6 and $9 \%$ ). The behaviors of both unmodified and modified binder were checked for rheological properties. Dynamic shear rheometer (DSR) was used to determine high temperature performance grade (PG) and multiple stress creep recovery tests to determine rutting resistance properties of the binder. PG analysis indicates that both aged and un-aged $3 \%$ and $6 \%$ modified binder have similar higher PG grade with the unmodified one and $9 \%$ modified to have lower PG vale. Jnr3.2 value of modified asphalt binder is lower than unmodified binder indicating that modification had improved the rutting resistance and design traffic load (ESALS). The study shows that it is possible to use waste engine oil-modified binder as a pavement material.
\end{abstract}

Keywords: Pavement material, Asphalt, Dynamic Shear Rheometer, Rheology, Rutting, Engine oil.

\section{Introduction}

The increase in cost of virgin asphalt made engineers to search new material that replace asphalt binder and attain the property of asphalt binder [1]. The mechanical property of asphalt binder and the long life behavior of constructed road depend on the properties of asphalt binder; good characteristics of asphalt will provide good quality of constructed road [2-7]. Behavior of asphalt binder can be investigated using modern super performance test method MSCR using dynamic shear rheometry. During MSCR test a small amount of asphalt binder is placed between two parallel plates held at constant temperature medium, especially distilled water, with the bottom of the plate fixed and top plate oscillating at the different angular frequency to each other [8] Multiple stress creep recovery test contains the provision of 10 cycles of creep and recovery shear loading [7]. The use of WEO on recycled asphalt mixture can change the stiffing behavior of hot mix asphalt [19].

For each loading cycle initial strain, Maximum strain at the end of creep and strain at the end of recovery are recorded, which are used to determine non-recoverable creep compliance and percent recovery
Stevens [9] Rutting vulnerability of the binder is determined by calculating the non-recoverable creep compliance (Jnr) and percent recovery (R) from measured data. In the rheological determination of polymer modified asphalt MSCR is better to represent the permanent deformation than performance grade [10]. Current super performance specification using complex modules $\left(\mathrm{G}^{*}\right)$ and phase angle $(\delta)$ are measured in linear viscoelastic range which is not sensitive to load level applied [3].

The commonly used DSR [3] test is not enough to characterize viscoelastic properties of polymer modified binder [6]. MSCR test combines the deeprooted creep and recovery test concept in order to assess the binder's latent for rutting. Traditionally, the MSCR test is conducted at two stress levels $(0.1$ and $3.2 \mathrm{kPa}$ ); at each stress level, asphalt binder specimens are subjected to ten cycles of loading and recovery [6]. Creep is a pattern of pavement faller which mostly occurred on the surface of pavement due to heavy loading, high tire pressure and heavy traffic [11-19]. Both asphalt binder and engine oil are the co product of petroleum production, so engine oil has sufficient aromatic and reassembles to asphalt binder this property makes WEO as modifier of bitumen [11]. 
Due to its similarity with chemical composition, the waste engine oil has a degree of compatibility with asphalt binder [12]. Waste engine oil has a significant effect on softening and improves elastic and recovery property of asphalt binders [12]. The provision of WEO in aged asphalt binder increases the rut depth, and the rut depth increase with increasing the content of WEO [14]. Low temperature performance of asphalt binder can be enhanced by the provision of WEO as a rejuvenator because WEO has low stiffness and rapid stress relaxation when provided into asphalt binder [15]. The provision of WEO in recycled asphalt pavement can decrease the viscosity and increase rut resistance of mixture [16]. Asphalt modified with WEO and SBS is good rutting and fatigue resistance, durable, and it is not moisture susceptible [16]. Addition of discarded engine oil in aged asphalt binder is making the decrease the complex modulus vale and increase phase angle, WEO can be used as a rejuvenator by the provision of elasticity and flexibility for a given asphalt binder [17]. Mass loss increase with increasing content of WEO. Higher WEO, cause in the decrease of higher and lower PG temperature. WEO increase the elastic recovery value of original bitumen [18]. Figure 2.3 indicate that as the content of waste engine oil modifier increase there is increase in mass loss and decrease in higher temperature PG grade, but the increase in mass loss and decrease in PG temperature depends on the type of asphalt binder. Waste engine oil has rejuvenation capacity on short term aged asphalt binder [12].

\section{Materials and Research Methods}

\subsection{Materials and Equipment}

The materials used for the study were bitumen and waste engine oil. The apparatus used for the research is dynamic shear rheometry (DSR) to determine rheological properties of binder, motorized blenders for the production of the modified specimen. The asphalt binder used in the study was 80/100 Penetration Grade bitumen Lubricating oil or engine oil.

\subsection{Rheological test using DSR}

DSR can characterize the viscoelastic behavior of bitumen by measuring of complex modulus and phase angle at different temperatures, frequencies, stress, and strain level [12]. Phase angle and complex modulus determine the rutting and fatigue behavior of the binder. This test is done for a temperature between 3-88 ${ }^{\circ} \mathrm{C}$. DSR test is conducted on unaged, RTFO aged and PAV aged bitumen, but for this study, DSR was done for unaged and RTFO aged asphalt binder.

\section{Result and Discussion}

\subsection{Higher temperature performance grade (PG) grade}

The main objective of performance grade test is determine the grade of a given asphalt binder. It is done at high-temperature oscillatory loading using DSR in $6^{\circ} \mathrm{C}$ temperature rise at high temperature (starting from $46^{\circ} \mathrm{C}$ ). If a given asphalt binder passes the first nominated temperature, it will pass to the next $6^{\circ} \mathrm{C}$ incremental temperature. The study use $\mathrm{G}^{*} / \sin \delta$ to determine the maximum temperature that the asphalt binder could meet the minimum criteria of AASHTO M320. The failure criteria are based on $G^{*} / \sin \delta$ value, which is considered the indicator of asphalt binder deformation at high pavement temperature. unaged minimum criteria $1 \mathrm{kpa}$ assures against tenderness mixture while RTFO aged $2.2 \mathrm{kpa}$ minimum criteria indicate the resistance of permanent deformation. PG determination DSR outputs for the study are summarized in table blow.

Table 1 PG result of RTFO aged binder

\begin{tabular}{|c|c|c|c|c|c|}
\hline WEO (\%) & $\mathrm{T}\left({ }^{\circ} \mathrm{C}\right)$ & Kpa & Status & Fail $\mathrm{T}\left({ }^{\circ}\right)$ & Higher PG Grade \\
\hline \multirow[t]{3}{*}{0} & 58 & 5.93 & Pass & \multirow[t]{3}{*}{65.35} & \multirow[t]{3}{*}{$64-Y Y$} \\
\hline & 64 & 2.64 & Pass & & \\
\hline & 70 & 1.20 & Fail & & \\
\hline \multirow[t]{3}{*}{3} & 58 & 8.98 & Pass & \multirow[t]{3}{*}{66.7} & \multirow[t]{3}{*}{$64-Y Y$} \\
\hline & 64 & 3.2 & Pass & & \\
\hline & 70 & 1.43 & Fail & & \\
\hline \multirow[t]{3}{*}{6} & 58 & 6.53 & Pass & \multirow[t]{3}{*}{65.8} & \multirow[t]{3}{*}{$64-Y Y$} \\
\hline & 64 & 2.79 & Pass & & \\
\hline & 70 & 1.23 & Fail & & \\
\hline \multirow[t]{3}{*}{9} & 52 & 4.33 & Pass & \multirow[t]{3}{*}{61.7} & \multirow[t]{3}{*}{$58-Y Y$} \\
\hline & 58 & 3.67 & Pass & & \\
\hline & 64 & 1.61 & Fail & & \\
\hline
\end{tabular}




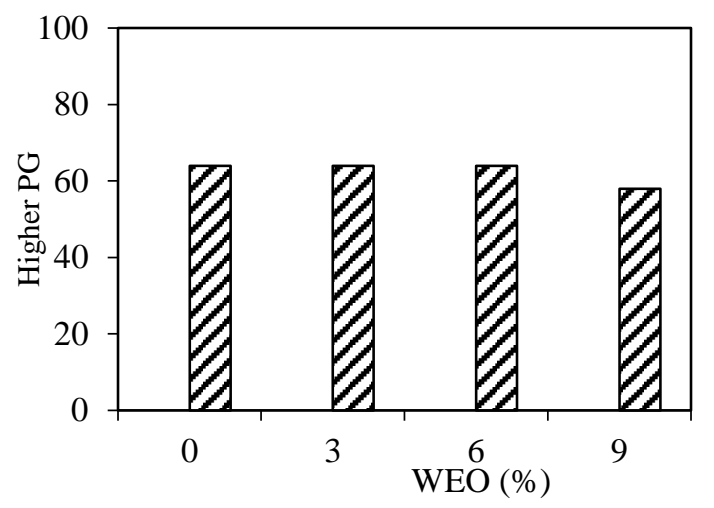

Figure 1 Higher PG grade for RTFO aged binder

Table 2 PG grade for unaged binder

\begin{tabular}{|l|l|l|l|l|l|}
\hline WEO (\%) & $\mathrm{T}\left({ }^{\circ} \mathrm{C}\right)$ & Kpa & Status & Fail T $\left(^{\circ}\right)$ & Higher PG Grade \\
\hline 0 & 52 & 5.20 & Pass & 63.8 & $64-Y Y$ \\
\cline { 2 - 4 } & 58 & 2.17 & Pass & & \\
\cline { 2 - 4 } & 64 & .97 & Fail & & \\
\hline 3 & 52 & 3.43 & Pass & 60.5 & $64-Y Y$ \\
\cline { 2 - 4 } & 58 & 1.38 & Pass & & \\
\cline { 2 - 4 } & 64 & 0.63 & Fail & & \\
\hline 6 & 52 & 2.78 & Pass & 59.1 & $64-Y Y$ \\
\cline { 2 - 4 } & 58 & 1.15 & Pass & & \\
\cline { 2 - 4 } & 64 & 0.51 & Fail & & \\
\hline 9 & 46 & 2.33 & Pass & 55.9 & $58-Y Y$ \\
\cline { 2 - 3 } & 52 & 1.77 & Pass & & \\
\cline { 2 - 4 } & 58 & 0.75 & Fail & & \\
\hline
\end{tabular}

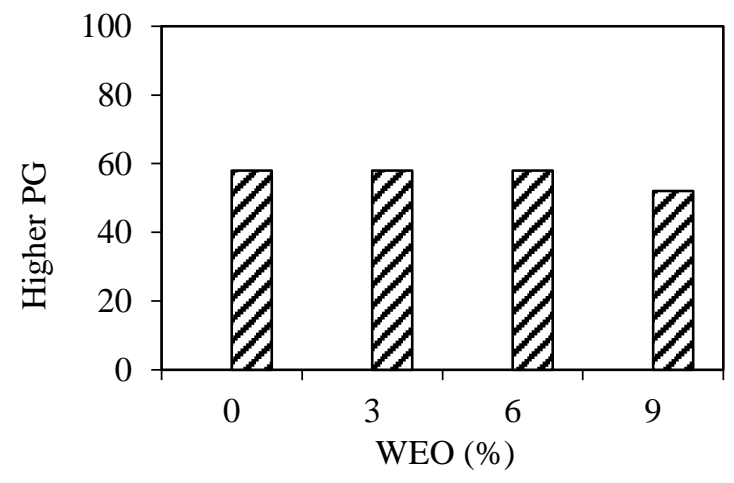

Figure 2 Higher PG grade for unaged binder

From the above table and figure, it possible to postulate that as the content of waste engine oil increase the higher PG value remain constant up to $6 \%$ and then it decreases. Pass /fail temperature of $3 \%$ WEO modified binder have higher pass/fail temperature.

From the above table and figure it is possible to concluded that provision of WEO as modifier does not improve the PG grade of the binder for both RTFO aged and unaged binder. Higher PG grade is similar to unmodified binder at 3and 6\% WEO content and at 9\% higher $P G$ value is small relative to the unmodified binder. Provision of 3 and $6 \%$ WEO as modifier have similar effect on the performance grade of binder. The lower the PG grades the low resistance to permanent deformation. 


\subsection{Multiple stress creep recovery (MSCR)}

MSCR test is conducted after the PG test is performed. The $P G$ high temperature is key to choose the test temperature for the MSCR test. Accordingly, the first test temperature for the MSCR test is at PG high temperature. The test is performed at $6^{\circ} \mathrm{C}$ increment or decrement from higher PG value.

Table 3 MSCR test temperature based on PG

\begin{tabular}{|l|l|l|l|l|}
\hline WEO $(\%)$ & PG Grade $\left({ }^{\circ} \mathrm{C}\right)$ & \multicolumn{3}{|c|}{ Test temperature $\left({ }^{\circ} \mathrm{C}\right)$} \\
\hline 0 & 64 & 58 & 64 & 70 \\
\hline 3 & 64 & 58 & 64 & 70 \\
\hline 6 & 64 & 58 & 64 & 70 \\
\hline 9 & 58 & 52 & 58 & 64 \\
\hline
\end{tabular}

\subsubsection{Terms in MSCR test}

Percent recovery value is an indication of elastic response and stress dependency of modified and non-modified asphalt binder.

It is a measure of how much sample returns to its original shape after a given load applied load is removed.

$$
\begin{aligned}
& R_{0.1}=\frac{\Sigma(\varepsilon r 0.1, N)}{10} \\
& R 3.2=\frac{\sum(\varepsilon r 0.3, N)}{10}
\end{aligned}
$$

Non recoverable creep compliance (Jnr) is remaining strain in sample after creep and recover divided by applied strain. It measure stress sensitivity of a given aged binder.

$$
\mathrm{Jnr}, 3.2 \mathrm{kpa}=\frac{\varepsilon 10}{3.2}, \mathrm{Jnr}, 0.1 \mathrm{kpa}=\frac{\varepsilon 10}{0.1} \quad 3
$$

Percent elastic recovery difference (\%) is the variation of elastic difference in percent between elastic recovery @ 0.1kpa and 3.2kpa applied strain.

$$
\begin{aligned}
& \text { Percent Recovery }=\frac{(\text { strain@1sec.- } \text { strain@ } @ 10) * 100}{\text { stain@1sec }} \\
& \left(\mathrm{Jnr}_{\mathrm{diff}}\right)=\frac{(j n r, 3.2 \mathrm{kpa}-\mathrm{jnr}, 0.1 \mathrm{kpa}) * 100}{(j n r, 01 \mathrm{kpa})}<=75 \% 4
\end{aligned}
$$

\subsubsection{MSCR test results}

The main output of MSCR test output used to determine the behavior of the asphalt binder are percent recovery, non-recoverable creep compliance, percent elastic recovery difference and percent difference in non- recovery creep compliance. The parameter properties are depends up on test temperature and loading rate.

(b)
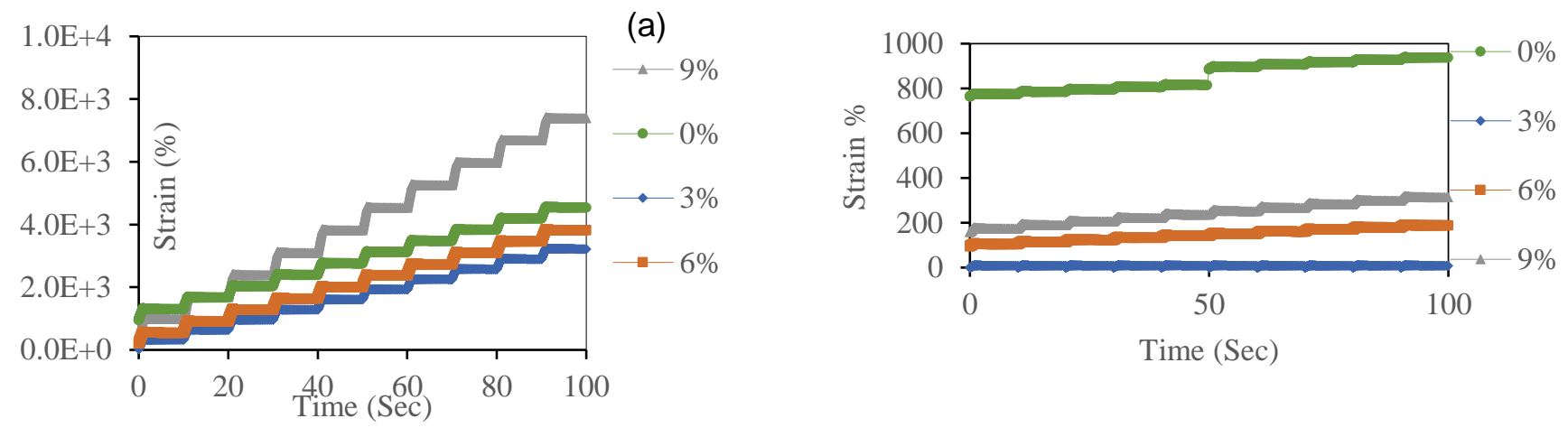

Figure 3 Effect of WEO on total strain at $58^{\circ} \mathrm{c}$ (a) $3.2 \mathrm{Kpa}$ (b) $0.1 \mathrm{kpa}$

Table 4 Summary of MSCR parameters for $0 \%$ WEO modified binder

\begin{tabular}{|l|l|l|l|}
\hline \multirow{2}{*}{ Description } & \multicolumn{3}{|l|}{ Test Temperature $\left({ }^{\circ} \mathrm{C}\right)$} \\
\cline { 2 - 4 } & 58 & 64 & 70 \\
\hline Recovery at $0.1 \mathrm{kPa}$ & 19.02 & 12.31 & 7.42 \\
\hline Recovery at $3.2 \mathrm{kPa}$ & 7.03 & 2.39 & 0.50 \\
\hline Jnr at $0.1 \mathrm{kPa}$ & 1.00 & 2.41 & 6.45 \\
\hline Jnr at $3.2 \mathrm{kPa}$ & 1.09 & 2.80 & 7.68 \\
\hline Jnr Difference (\%) & 9.69 & 16.43 & 19.09 \\
\hline PG Grade & \multicolumn{3}{|c|}{64} \\
\hline
\end{tabular}


Table 5 Summary of MSCR parameters for $3 \%$ WEO

\begin{tabular}{|l|l|l|l|}
\hline \multirow{2}{*}{ Description } & \multicolumn{3}{|l|}{ Test Temperature $\left({ }^{\circ} \mathrm{C}\right)$} \\
\cline { 2 - 4 } & 58 & 64 & 70 \\
\hline Recovery (\%) $0.1 \mathrm{kPa}$ & 23.83 & 17.93 & 10.43 \\
\hline Recovery (\%) at $3.2 \mathrm{kPa}$ & 9.72 & 2.97 & 0.86 \\
\hline Jnr at $0.1 \mathrm{kPa}$ & 0.82 & 2.17 & 5.22 \\
\hline Jnr at $3.2 \mathrm{kPa}$ & 0.97 & 2.94 & 6.87 \\
\hline Jnr Difference (\%) & 17.35 & 35.70 & 31.44 \\
\hline PG Grade & \multicolumn{3}{|c|}{64} \\
\hline
\end{tabular}

Table 6 Summary of MSCR parameters for $6 \%$ WEO modified binder

\begin{tabular}{|l|l|l|l|}
\hline \multirow{2}{*}{\multicolumn{1}{|c|}{ Description }} & \multicolumn{3}{c|}{ Test Temperature $\left({ }^{\circ} \mathrm{C}\right)$} \\
\cline { 2 - 4 } & 58 & 64 & 70 \\
\hline Recovery at 0.1kPa & 26.80 & 20.34 & 11.48 \\
\hline Recovery at 3.2kPa & 9.45 & 2.81 & 0.65 \\
\hline Jnr at 0.1 kPa & 0.89 & 2.46 & 6.21 \\
\hline Jnr at 3.2 kPa & 1.09 & 3.48 & 8.62 \\
\hline Jnr Difference (\%) & 22.30 & 41.38 & 38.84 \\
\hline PG Grade & & \multicolumn{3}{|c|}{64} \\
\hline
\end{tabular}

Table 7 Summary of MSCR parameters for $9 \%$ WEO modified binder

\begin{tabular}{|l|l|l|l|}
\hline \multirow{2}{*}{ Description } & \multicolumn{3}{|l|}{ Test Temperature $\left({ }^{\circ} \mathrm{C}\right)$} \\
\cline { 2 - 4 } & 52 & 58 & 64 \\
\hline Recovery at $0.1 \mathrm{kPa}$ & 37.03 & 26.50 & 18.82 \\
\hline Recovery at 3.2kPa & 14.41 & 4.62 & 1.29 \\
\hline Jnr at $0.1 \mathrm{kPa}$ & 0.55 & 1.49 & 4.04 \\
\hline Jnr at 3.2 kPa & 0.78 & 2.14 & 6.34 \\
\hline Jnr Difference (\%) & 40.69 & 43.30 & 57.38 \\
\hline PG Grade & \multicolumn{4}{|l|}{64} \\
\hline
\end{tabular}

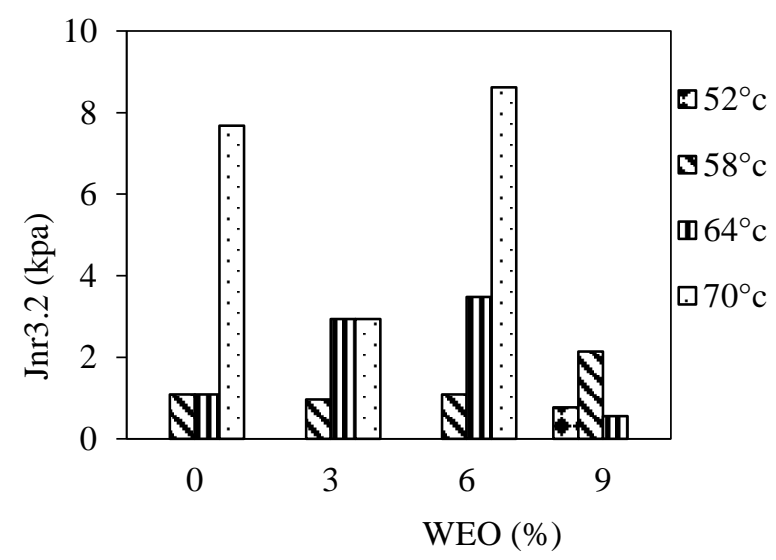

Figure $4 \mathrm{Jnr}(3.2 \mathrm{Kpa})$ value at different content of modification 
Table 8 Binder specification requirements based on MSCR test

\begin{tabular}{|l|l|l|l|}
\hline Traffic Design & Traffic Level (ESALs), $10^{6}$ & Load Rate $(\mathrm{Km} / \mathrm{h})$ & Jnr 3.2, Max (Kpa-1) \\
\hline Standard "S" & $<10$ & $>70$ & 4.5 \\
\hline Heavy "H" & 10 to 30 & $20-70$ & 2 \\
\hline Very heavy "V" & $>30$ & $<20$ & 1 \\
\hline a Extremely Very Heavy "E" & $>30$ & $<20$ & 0.5 \\
\hline
\end{tabular}

The above figures illustrate the effects of WEO on the total strain of the binder at 0.1 and $3.2 \mathrm{kpa}$ stresses. As the percent of modifier rise there is rise in the strain value on the creep and recovery process that is shown in the above figure for both loading conditions (0.1 kpa and $3.2 \mathrm{kpa})$.

As indicated in the terms in MSCR test section the basic output of the test that define the property of a given asphalt binder are percent recovery $(R)$, nonrecoverable creep compliance (Jnr0.1 and Jnr3.2kpa) and percent recovery difference. Those parameters are tabulated below for each binder type.

From the above tables it can be postulated on WEO modification on the behavior of asphalt binder, as follows:

- At the same temperature percent recovery of all modified binder is higher than the unmodified one. This indicated that WEO increases the elastic property of the asphalt binder, hence decreasing the stiffness of binder.

- Percent recovery of the binder is dependent on the applied shear stress, the percent recovery strain is higher at $0.1 \mathrm{kpa}$ of shear stress than 3.2 $\mathrm{kpa}$, and also it is dependent on the pavement temperature when the temperature increases the elastic recovery decrease and vise verse making the binder viscous material.

- The non-recoverable creep compliance (Jnr) value at 3.2 is a fundamental parameter to evaluate rutting potential. The lower Jnr3.2, the higher the rutting resistance may occur. As it can be seen from the above table Jnr value at similar temperature but the WEO content is different. Hence, this indicated that rutting resistance of a given asphalt binder is dependent on the amount of modifier.

- When the pavement temperature increase, the non-recoverable creep compliance value also increases for the binder. This is due to the behavior of asphalt binder that is more viscous at higher temperatures, which results in a higher permanent strain of the material under stress.
AASHTO MP-19 has briefly labeled requirement for performance grade asphalt binder using MSCR test.

Based on AASHTO MP-19 as described on the table Jnr $3.2 \mathrm{kpa}$ is the main parameter to define the rutting resistance of a given asphalt binder. Based on the jnr3.2 value and the AASHTO requirement the following conclusion can be postulated.

- According to AASHTO MP-19, when Jnr 3.2 value increase, rutting resistance decrease, and design traffic ESALs decrease. In the above figure at equivalent temperature, Jnr3.2 value of un modified asphalt binder is higher than modified binder indicating that modification had improve the rutting resistance and design traffic load (ESALS).

- From all modified binder, 3\% WEO modified binder have lower Jnr3.2 value which indicate that the binder have high rutting resistance and can be used for very heavy vehicle.

- Both modified and unmodified binders are not desirable to use for extremely very heavy traffic class.

- Unmodified and modified (3 and 6\%) asphalt binder are desirable for environmental temperature blow $64^{\circ} \mathrm{C}$ and $9 \%$ modified binder for maximum environmental temperature of $58^{\circ} \mathrm{C}$.

\section{Conclusion}

The aim of the study was to evaluate waste engine oil modified asphalt binder as pavement material using MSCR test and to evaluate the effect of this modifier on the rheological property. Based on results of the laboratory output, the following conclusions are drawn:

- The PG value of $0 \%$ modified asphalt binder is similar with $3 \%$ and $6 \%$ modified binder while at 9\% modification the PG value is decreased for both unaged and RTFO aged binder.

- unaged $0 \%, 3 \%$ and $6 \%$ modified binder have $P G$ value of PG58-YY and 9\% have PG of PG52-YY 
but RTFO aged $0 \%, 3 \%$ and $6 \%$ modified binder are PG64-YY and 9\% modified binder is PG58-YY.

- At the same temperature percent recovery of all modified binder is higher than the unmodified one. This indicated that WEO increases the elastic property of the asphalt binder, hence decreasing the stiffness.

- Jnr3.2 value of unmodified asphalt binder is lower than modified binder indicating that modification had improved the rutting resistance and design traffic load (ESALS).3\% WEO modified binder have lower Jnr3.2 value which indicate that the binder have high rutting resistance and can be used for very heavy vehicle.

- Based on the study both aged and unaged modified binder cannot be used for very heavy traffic class.

- Asphalt binder modified by waste engine have bad smell property, which may cause undesirable condition during construction of the road, so investigation of material that will change this bad odder may be the next move of the research.

\section{References}

[1] M. M. A. Aziz, M. T. Rahman, M. R. Hainin, W. A. Bakar, An overview of alternative binders for flexible pavement, Construction and Building Materials, 84 (2015) 315-319. [DOI]

[2] S. Arafat Yero, M. R. Hainin, The influence of short-term aging on bitumen properties, ARPN Journal of Science and Technology, 2 (2012) 597-599.

[3] AASHTO T315: Dynamic Shear Rheometer, AASHTO, Washington, D.C., 2011

[4] AASHTO, Determining the rheological properties of asphalt binder using a dynamic shear rheometer (DSR), AASHTO T315, Washington, DC, (2010a).

[5] AASHTO, Standard specification for performance-graded asphalt binder using multiple stress creep recovery (MSCR) test, AASHTO MP19, Washington, DC, (2010b).

[6] Z. Hossain, D. Ghosh, M. Zaman, K. Hobson, Use of the Multiple Stress Creep Recovery (MSCR)Test Method to Characterize PolymerModified Asphalt Binders, Journal of Testing and Evaluation, 44 (2016) 507-520.

[7] J. Documents, Multiple Stress Creep Recovery (MSCR) Test of Asphalt Binder Using a Dynamic Shear Rheometer (DSR), (2013) 1-7.

[8] P. Interactive, S.Pg, Dynamic Shear Rheometer, (2011) 1-7.

[9] R. Stevens, Evaluation of Multiple Stress Creep and Recovery (MSCR) Data for Arizona, 1(1997) 337-345.

[10] M. Anderson, Understanding the MSCR Test and its Use in the $P G$ Asphalt Binder Specification Recording, (2014).
[11]

A.A. Mamun, H.I. Al-Abdul Wahhab, Evaluation of Waste Engine Oil-Rejuvenated Asphalt Concrete Mixtures with High RAP Content, Advances in Materials Science and Engineering, 2018 (2018). [DOI]

[12] Biruk Tadele, Emer Tucay Quezon, Evaluation of waste engine oil rejuvenation for highly short-term aged asphalt binder, Australian Journal of Civil Engineering, 19 (2021) 225234. [DOI]

[13] P.K.S. Brito, D. F. Carvalho, M. C. P. A. Moura, E. L. Barros Neto, T. N. C. Dantas, A. A. Dantas Neto, Development of Asphalt Emulsions Incorporating Waste Lubricating Oil, Brazilian Journal of Petroleum and Gas, 9 (2015)167-176. [DOI]

[14] S.B. Cooper, L.N. Mohammad, M.A. Elseif, Laboratory performance of asphalt mixtures containing recycled asphalt shingles and rerefined engine oil bottoms, Journal of Materials in Civil Engineering, 29 (2017) 1-6. [DOI]

[15] Z. Lei, H. Bahia, T. Yi-Qiu, Effect of bio-based and refined waste oil modifiers on low temperature performance of asphalt binders, Construction and Building Materials, 86 (2015) 95-100. [DOl]

[16] S. Fernandes, Improving asphalt mixture performance by partially replacing bitumen with waste motor oil and elastomer modifiers, Applied Sciences, (2017) 1-11. [DOI]

[17] A.K. Swamy, I.A. Qurashi, Viscoelastic properties of recycled asphalt binder containing waste engine oil, Journal of Cleaner Production, 182 (2018) 992-1000. [DOI]

[18] Wu. Shenghua, Balasingam Muhunthan, Evaluation of the Effects of Waste Engine Oil on the Rheological Properties of Asphalt Binders, Journal of Materials in Civil Engineering, 30 (2018) 1-5. [DOI]

[19] N.A. Hassan, N.H.M. Kamaruddin, M.R. Hainin, M.E. Abdullah, Effect of Warm Asphalt Additive on the Creep and Recovery Behaviour of Aged Binder Containing Waste Engine Oil, IOP Conference Series: Materials Science and Engineering, 226 (2017) 012066. [DOI]

\section{Acknowledgment}

The Authors would like to express their deep gratitude to the Civil Engineering Laboratory of AASTU for allowing the researchers to conduct experiments at a minimal cost.

\section{Conflict of interest}

The Authors have no conflicts of interest to declare that they are relevant to the content of this article.

\section{Does this article screened for similarity?}

Yes

\section{About the License}

(C) The Author(s) 2022. The text of this article is open access and licensed under a Creative Commons Attribution 4.0 International License. 